NEWS

\title{
Wildlife service plans for a warmer world
}

\author{
US interior department seeks ways to save species \\ threatened by climate change.
}

Akikikis are small birds with limber tongues that are adept at pulling insects from the crevices in tree bark. The olive-and-white birds are also headed towards extinction. Earlier this month, the US Fish and Wildlife Service (USFWS) listed the akikiki as endangered and warned that global warming may hasten its disappearance by prompting the spread of avian malaria.

The akikiki is just one of more than 200 birds in the United States threatened by climate change, according to a report issued last week by the US Department of the Interior, which oversees the USFWS. Called The State of the Birds: 2010 Report on Climate Change, it is one of several steps recently taken by the administration of President Barack Obama to assess how climate change is affecting wildlife and to find ways of lessening its impact.
"For too long, in my view, we have stood idle as the climate-change crisis has grown," says Ken Salazar, secretary of the interior department. Mike Daulton, legislative director of the National Audubon Society in New York City, agrees. "We are getting a late start," he says.

The report, a collaboration between the USFWS, the US Geological Survey, academics and a collection of environmental and wildlife groups, quantified the vulnerability of each species on the basis of its breeding behaviour, habitat, migratory pattern and ecological niche. George Wallace, vice-president for oceans and islands at the American Bird Conservancy in The Plains, Virginia, says the report shows that "we need to consider climate change as we continue conservation work into the future".

Climate change will magnify already existing threats to birds, says Kenneth Rosenberg



from the Cornell Lab of Ornithology in Ithaca, New York. Every habitat will be disrupted by the warming climate, but ocean birds are the most vulnerable to the disruption, with all 67 species especially at risk because they depend on a rapidly changing marine ecosystem, according to the report. And island birds, particularly those in Hawaii, will face increasing rates of avian malaria if the warming climate allows mosquitoes to spread to higher mountain zones.

The USFWS this month added the akikiki and another bird from the Hawaiian island of

\section{Sex bias blights drug studies}

The typical patient with chronic pain is a 55-year-old woman - the typical chronic-pain study subject is an 8-week-old male mouse. To pain researcher Jeffrey Mogil at McGill University in Montreal, Canada, that discrepancy is a telling example of the problem that he and other neuroscientists discussed last week at a workshop held in San Francisco, California: the serious under-representation of females in biomedical studies.

The lack of female participation, which extends from basic research in animals to clinical trials in humans, has obvious consequences for women, not least a paucity of effective drug treatments for diseases that predominantly affect them. But it also affects men, for example when drug candidates fail to get regulatory approval because they don't work in women in late-stage clinical trials, or have severe side effects in women that are not seen in men. Such failures might be spotted earlier if more preclinical work was done in female model animals, according to researchers at the Workshop on Sex Differences and Implications for Translational Neuroscience

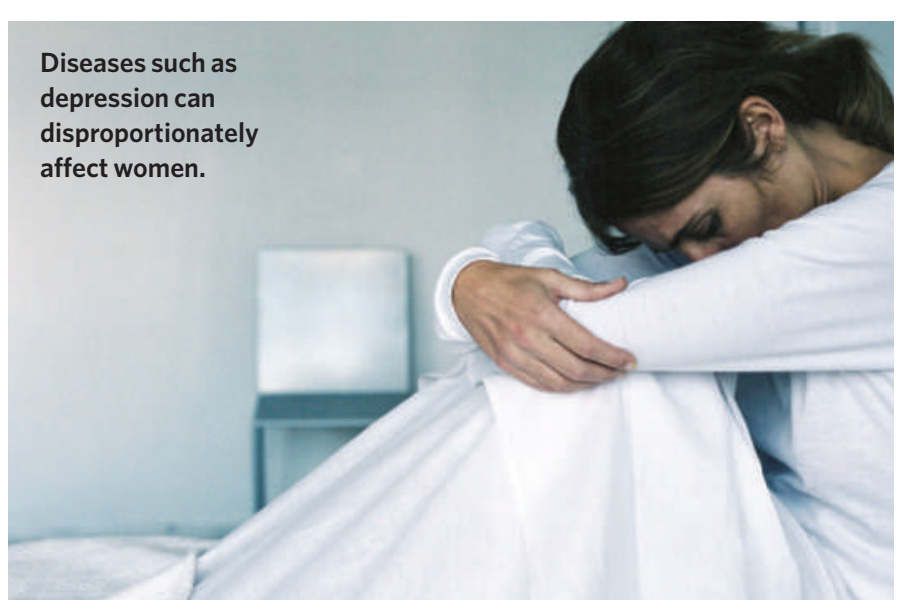

Research, convened on 8-9 March by the US Institute of Medicine's Forum on Neuroscience and Nervous System Disorders.

"This is an issue of enormous importance," says biologist Irving Zucker at the University of California, Berkeley. "In a number of disciplines, researchers simply don't study females, and there is so much evidence for sex differences at all levels of biological organization that to only study males, and assume the results apply to females, is just wrong."

Many diseases disproportionately affect one sex: chronic pain, depression and autoimmune disease, for instance, more often affect women, with addiction and cardiovascular disease disproportionately affecting men. The NIH Revitalization Act of 1993 attempted to take account of this by requiring clinical trials funded by the National Institutes of Health to include adequate numbers of women to detect differing treatment effects.

The US Government Accountability Office reported in 2000 that participation of women 


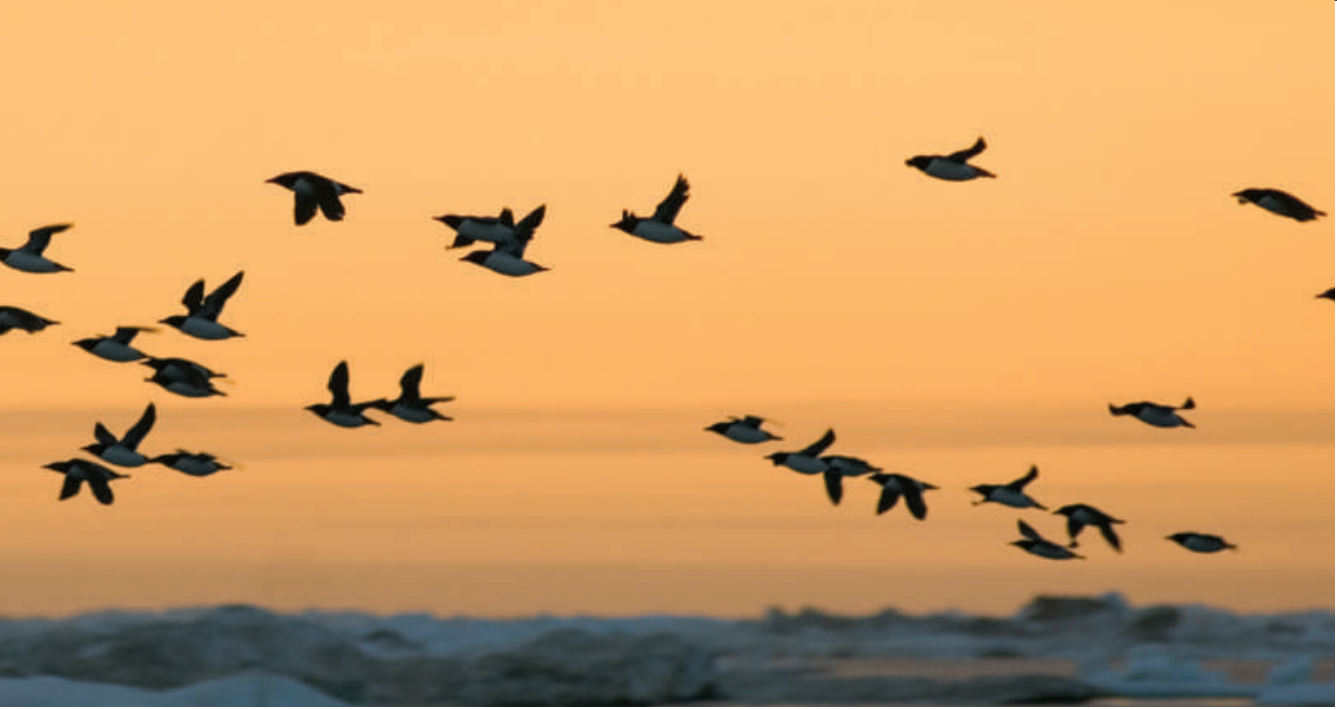

Climate change threatens some 200 bird species in the United States, especially marine birds.

Kauai to its endangered-species list. Also joining the list is a picture-wing fly and 45 plant species from Kauai. Because they are all endemic to the island, climate change poses a special risk to them, according to the wildlife service.

Last month, Salazar issued an order marshalling the forces of the interior department to study climate impacts on wildlife, and earlier this month the department opened a Climate Science Center in Anchorage, Alaska, the first of eight planned around the nation. Information from those centres about climate's effects and ways to lessen them will feed into a network of Landscape Conservation Cooperatives, which will help to coordinate regional climate-adaptation efforts by federal and state governments and private landowners.

"It's a daunting task for a refuge manager sitting on the eastern shore of Maryland to understand what climate change means for

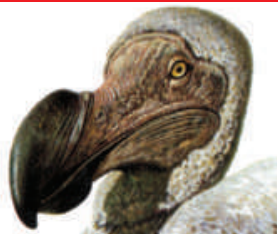

WHEN IS A SPECIES EXTINCT?

Model assesses whether conservation is viable.

go.nature.com/hWL6tA

the Chesapeake," says Paul Schmidt, USFWS assistant director for migratory birds. "We must scale down those big climate models to help the manager on the ground."

Meanwhile, wildlife managers are taking several approaches to counteract the effects of climate change. In Hawaii, for example, one tactic to save rare birds involves keeping large mammals out of sensitive areas. This prevents the animals from trampling the ground, which destroys habitat and also creates water-filled hollows where mosquitoes can breed.

Environmental groups have charged that the previous administration of George W. Bush ignored climate change and its effects. But Paul Hoffman, who served as deputy assistant secretary for fish, wildlife and parks under Bush, says it would be wrong to suggest that officials ignored the science. "Quite often, the scientists weren't in agreement about the problem and what the solution ought to be," he adds.

But the Obama administration's first budget reflects a change in priorities. For fiscal year 2010 , it provided US $\$ 25$ million for Landscape Conservation Cooperatives and $\$ 15$ million for Climate Science Centers. "It went from zero to $\$ 40$ million in one year," Schmidt says. Steve Holmer of the American Bird Conservancy calls these efforts "a pretty impressive systematic approach across the board".

Janet Fang

in NIH-funded trials had increased substantially (see www.gao.gov/ archive/2000/he00096.pdf). The following year, it noted similar progress in late-stage drug trials overseen by the Food and Drug Administration (see www.gao.gov/ new.items/d01754.pdf).

But data from clinical trials are often not analysed separately on the basis of sex. Such analyses could reveal whether a drug has different adverse effects in men and women, for example.

And the accountability office also noted in $\mathbf{2 0 0 1}$ that although women made up more than half of full-scale safety and efficacy trials, they formed just $22 \%$ of the participants in initial, small-scale safety studies.

Back at the bench, lab animals are still predominantly male, even in studies of diseases that disproportionately affect women. Investigators tend to prefer male animals because it is thought that females might introduce variability through factors such as their oestrous cycles. But Mogil has reported that in common tests used to measure responses to pain, data from female mice are no more variable than those from males (J. S. Mogil and M. L. Chanda Pain 117, 1-5; 2005).

The problem is particularly acute in neuroscience, in which the ratio of male- to female-only studies is 5.5 to 1 . But under-representation of females occurs in most fields of basic research, according to an unpublished analysis by Zucker and postdoctoral researcher Annaliese Beery. They investigated the use of female and male animals in research published during 2009 in 10 fields across 42 journals. They found that studies in eight of the fields used only male animals more often than only females, and that the data were often not analysed by sex. In two journals that the researchers investigated

back to 1909, the proportion of animal studies using only males had actually grown since the early twentieth century. The authors speculate that this is because oestrous cycles in guinea pigs, rats and mice were first clearly characterized only in the 1920s.

Researchers such as Karen

"To only study males, and assume the results apply to females, is just wrong."
Berkley of Florida State University in Tallahassee have been trying to boost female representation for decades, and Berkley feels that some progress has been made, citing, for example, the launch of an online journal in the field, Biology of Sex Differences, and an overall growth in research on sex differences.

But at the workshop, Berkley and other scientists agreed that further steps were needed to address the problem. Many endorsed the idea that journals should require their authors to report the sex of animals used in the research. The London-based National Centre for the Replacement, Refinement and Reduction of Animals in Research is developing a set of research reporting guidelines that will call for authors to disclose the sex of animals. Seán Murphy, chief editor of the Journal of Neurochemistry, says that there is "interest" in the guidelines among journal editors at its publisher, Wiley-Blackwell.

Researchers at the workshop said that funding agencies, too, could ask grant applicants to specify the sex of the animals they propose studying and justify their decision whenever they chose only male animals. Funders could also change the status quo, the researchers claimed, by supporting more work on sex differences, although the NIH would not comment on whether this was under consideration. Erika Check Hayden 